\title{
Effect of ultraviolet light irradiation on bond strength of fiber post: Evaluation of surface characteristic and bonded area of fiber post with resin cement
}

\author{
Fazal Reza ${ }^{1}$, Nur Sukainah Ibrahim²
}

Correspondence: Dr. Fazal Reza

'Department Prosthodontics Unit, School of Dental Sciences, Universiti Sains Malaysia, Malaysia,

${ }^{2}$ Goverment Dental Clinic, General Dentistry

Email: fazal.dent@gmail.com

Department, Kuala Pilah, Negeri Sembilan, Malaysia

\section{ABSTRACT}

Objective: Fiber post is cemented to a root canal to restore coronal tooth structure. This research aims to evaluate the effect of ultraviolet (UV) irradiation on bond strength of fiber post with resin cement. Materials and Methods: A total of 40 of the two types of fiber posts, namely, FRC Prostec (FRC) and Fiber KOR (KOR), were used for the experiment. UV irradiation was applied on top of the fiber post surface for $0,15,20$, and $30 \mathrm{~min}$. The irradiated surface of the fiber posts $(n=5)$ were immediately bonded with resin cement (Rely X U200) after UV irradiation. Shear bond strength (SBS) MPa was measured, and the dislodged area of post surfaces was examined with scanning electron microscopes. Changes in surface roughness (Ra) of the FRC group after UV irradiation were observed $(n=3)$ using atomic force microscopy. Data of SBS were statistically analyzed using one-way analysis of variance, followed by multiple comparisons $(P<0.05)$. Results: SBS was significantly higher for 20 min of UV irradiation of the FRC group while significantly higher SBS was observed with 15 min of UV irradiation of the KOR group. Resin cement was more evident (cohesive failure) on the dislodged post surface of the UV treated groups compared with the control. The surface roughness of the FRC post was $\mathrm{Ra}=175.1 \mathrm{~nm}$ and $\mathrm{Ra}=929.2 \mathrm{~nm}$ for the control and the 20 min group, respectively. Conclusions: Higher surface roughness of the UV irradiated group indicated formation of mechanical retention on the fiber post surface. Evidence of cohesive failure was observed which indicated higher SBS of fiber post with the UV irradiated group.

Key words: Bond strength, fiber post, ultraviolet light

\section{INTRODUCTION}

Endodontically treated teeth usually have minimum coronal tooth structure. Intra-canal posts are often necessary to restore or retain coronal restoration. ${ }^{[1]}$ Fiber-reinforced post, which has an elastic modulus similar to dentin, ${ }^{[2]}$ has gained popularity because of its satisfactory performance in providing better distribution of loads to the teeth than metal posts and low rate of root fracture, ${ }^{[3,4]}$ the most serious type of failure. Fiber post is cemented to the root canal of the tooth, and the core is built to support the cemented fiber post along the root canal. Therefore, the resin cement used to bond the fiber post has two interfaces, namely, fiber post/resin cement and resin cement/root dentin interfaces. The root or dentine/adhesive interface has been widely investigated. However, these studies were less focused on the weaker interface that is, the post/resin cement interface. ${ }^{[3]}$ The weak adhesion of resin cement to the fiber-reinforced post may be a result of the lack of strong chemical bonding between the resin cement and the polymerized epoxy or polyvinyl ester-type matrices of the fiber-reinforced post; thus, majority of bond failures have been observed between fiber post and resin cements. ${ }^{[5,6]}$

Mechanical and chemical treatments of fiber post surface, as well as changes in the post matrix composition, influence the bond strength between the resin materials and the fiber-reinforced posts. ${ }^{[7]}$ Several

\footnotetext{
How to cite this article: Reza F, Ibrahim NS. Effect of ultraviolet light irradiation on bond strength of fiber post: Evaluation of surface characteristic and bonded area of fiber post with resin cement. Eur J Dent 2015;9:74-9. 
surface treatments had been applied to fiber post surface, such as sandblasting treatment using $\mathrm{Al}_{2} \mathrm{O}_{3}$ particles, ${ }^{[8-12]}$ organic solvents like dichloromethane to etch fiber post surface, ${ }^{[8,11]}$ etching treatment with acidic solution like hydrogen fluoride, ${ }^{[8-11]}$ with silane coupling agents, ${ }^{[8-11]}$ plasma irradiation, ${ }^{[10-14]}$ and ultraviolet (UV) irradiation. ${ }^{[13,15,16]}$ Application of UV has been suggested because it may be able to change molecular structure of resin matrix ${ }^{[17-21]}$ and may be responsible in improving surface roughness at micro and/or nanometer level, thereby creating areas for mechanical interlocking. ${ }^{[17-20]}$ Most of the aforementioned chemical and physical treatments have their limitations because of technique sensitivity or cost and probable damage of fiber the post surfaces during application of a specific method.

Application of UV to induce photochemical changes resulting in oxidation of the exposed surface, modification of hydrophobic nature of the polymers, and increase in surface energy of polymers to improve the bond strength of denture base and artificial teeth have been reported. Recently, UV irradiation has been reported to improve the bond strength of fiber post system with resin cement. ${ }^{[16]}$ With regard to composition of resin cements, thermoplastic resins, such as the methacrylate monomer group, dominate the composition. "Interpenetrating polymer network (IPN)" is formed to achieve cohesive strength within the resin matrix of the thermoplastic type. However, the fiber post matrix resin is mostly comprise a thermosetting type and a highly cross-linked structure, such as urethane dimethacrylate (UDMA), triethylene glycol dimethacrylate (TEGDMA), bisphenol A-glycidyl methacrylate, and epoxy resin. As a result, no functional groups of fiber posts would react with the methacrylate group, which is the major component of dental composite resin, thereby resulting in the absence of chemical bonding between these two substrates. ${ }^{[22]}$ Thus, bonding of the two different types of resins (thermoplastic and thermosetting) is a matter of interest. Moreover, changes in surface characteristic of the fiber post surfaces after UV irradiation need more evidence. Therefore, the roughness of fiber post at nano/ micrometer level before and after UV exposure needs to be evaluated. Recent progress in relation to resin matrix composition of fiber post materials and resin cements leads to further investigation of bond strength measurement.

This study aims to evaluate the effect of UV irradiation on the bond strength of resin luting cement to fiber-reinforced post and the surface characteristics of the fiber post following UV irradiation. The null hypothesis tested was that UV irradiation would not affect the bond strength of resin cement to fiber post.

\section{MATERIALS AND METHODS}

\section{Post surface conditioning and luting procedure}

A total of forty translucent fiber-reinforced posts of two types, namely, FRC Prostec Plus (IvoclarVivadent, Schaan, Liechtenstein) (FRC) and Fiber KOR (Pentron, Wallingford, USA) (KOR), with a length of $20.0 \mathrm{~mm}$ and a maximum diameter of $2.0 \mathrm{~mm}$, were used for the experiments. The post surface was cleaned with $95 \%$ ethanol and dried with air stream. Self-cured acrylic resin was poured in a square shaped plastic mold (height $20 \mathrm{~mm} ; 12 \times 12 \mathrm{~mm}$ ) and the fiber post was embedded perpendicularly so that the top of the post surface coincided with the level of acrylic resin [Figure 1]. The top surface (diameter of $2 \mathrm{~mm}$ ) of the fiber post was exposed to bond with self-adhesive resin cement (SF CEM, 3M ESPE, Germany) to measure shear bond strength (SBS) (MPa). Materials with their compositions are shown in Table 1.

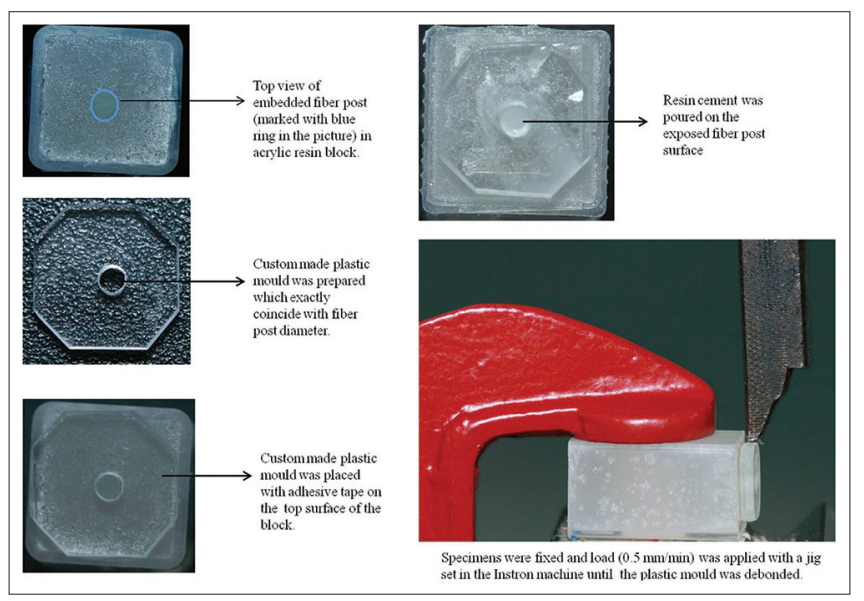

Figure 1: Specimen preparation and experimental set up to measure shear bond strength (MPa)

\begin{tabular}{ll}
\multicolumn{2}{l}{ Table 1: Materials used in the study } \\
\hline Materials & Main ingredients \\
\hline SF CEM (3M ESPE, & Methacrylate monomers, methacrylate \\
germany; lot MP 0062) a & monomers containing phosphoric \\
self-adhesive resin cement & acid group, silanated fillers \\
FRC prostec plus, ivoclar & TEGDMA (17.5\%), UDMA (18.3\%), \\
vivadent, USA; lot P02331 & glass fibers (61.5\%) \\
Fiber KOR post system & BISGMA, inorganic fillers and glass \\
pentron, USA; lot L146728R & fibers (40.9\%) in polymer matrix \\
\hline TEGDMA: Triethylene glycol dimethacrylate, UDMA: Urethane dimethacrylate, \\
BISGMA: Bisphenol A-glycidyl methacrylate
\end{tabular}


Twenty samples were used for each of the fiber post types and further divided into four groups for UV treatment with different duration $(n=5)$. In the control group, no UV irradiation was performed to the post surface. For groups 2, 3, and 4, the post surfaces were exposed to UV irradiation for 15, 20, and $30 \mathrm{~min}$, respectively. UV irradiation was applied to the top surface of the fiber post in a biosafety cabinet (Hera Safe, Germany). The post surface was placed $10 \mathrm{~cm}$ from the UV lamp with a wavelength of $253.7 \mathrm{~nm}$.

A cylindrical mold with an internal diameter of $2 \mathrm{~mm} \times$ height of $2 \mathrm{~mm}$ was prepared in a square shaped plastic plate. The plate was then placed over the top of the exposed fiber post so that the outside perimeter of the fiber post exactly matched with the prepared $2 \mathrm{~mm}$ diameter of the mold on one side. Resin cement was carefully poured on top of the exposed post surface to completely fill the plastic mold from the other side at its $2 \mathrm{~mm}$ height level [Figure 1]. The specimens were light polymerized for $40 \mathrm{~s}$ by a LED light curing unit (Bluedent LED smart, Bulgaria) with light intensity of more than $1200 \mathrm{~mW} / \mathrm{cm}^{2}$. A radiometer (CURERITE ${ }^{\mathrm{TM}}$ Dentsply ${ }^{\circledR}$ Caulk, USA) was used to confirm the light intensity of the LED lights before light curing the resin cement. After the polymerization process, specimens were stored in a dark container for approximately 2-3 h before SBS measurement.

\section{Shear bond strength (MPa) measurement}

Each specimen was mounted in a universal testing machine (Model 8874, Instron Corp., USA). A custom metal jig was set with the testing machine to apply the load at a crosshead speed of $0.5 \mathrm{~mm} / \mathrm{min}$ until the plastic ring was debonded from the top of the fiber post surface [Figure 1]. The SBS of the luting cement to the post was expressed in MPa by dividing the load $(\mathrm{N})$ at failure with the bonding surface area $\left(\mathrm{mm}^{2}\right)$ of the exposed fiber post surface.

\section{Scanning electron microscopy}

Scanning electron microscopy (SEM) (Phenom ${ }^{\mathrm{TM}}$, Eindhoven, The Netherlands) was used to observe the dislodged area of the post surface. Only the control and significantly higher bond strength group were analyzed for FRC and KOR group.

\section{Surface roughness (Ra) of fiber post surface}

Surface roughness of FRC before and after $20 \mathrm{~min}$ of UV exposure were observed $(n=3)$. For the convenience of measurement, the longitudinal surface of the post was used; the KOR group was excluded from the measurement because it has serrated the surface. Atomic force microscopy (AFM Q-Scope 250/400 Nomad, Ambios Technology Inc., Santa Cruz, USA) with contact mode was used to measure the roughness $(\mathrm{Ra})$ value. Surface roughness was measured within $30 \mathrm{~min}$ of UV irradiations. Silicone tips were employed at constant force of $0.15 \mathrm{~N} / \mathrm{m}$ and a resonant frequency of $1 \mathrm{~Hz}$ with mapping procedure $40 \times 40 \mu \mathrm{m}$.

For sample size calculation, related studies to this study were reviewed, and the closest study was chosen to measure the sample size. ${ }^{[16]}$ The variables in the present study met the criteria for a normal distribution; thus, parametric analysis was performed. The mean values of SBS (MPa) between groups were statistically analyzed using a one-way analysis of variance (ANOVA). Subsequent multiple comparisons between different groups were performed using the Tukey-test. Surface roughness ( $\mathrm{Ra}$ ) between groups was analyzed using $t$-test. For all tests, the alpha was equal to 0.05. All analyses were performed with statistical software (SPSS 20; SPSS, Inc., Chicago, USA).

\section{RESULTS}

\section{Shear bond strength}

The ANOVA results [Table 2] demonstrated a statistically significant difference of SBS between the control and UV irradiated groups. The mean and standard deviations of SBS are presented in Figure 2. Significantly higher SBS were observed for the groups irradiated for 20 and $15 \mathrm{~min}$ for the FRC and KOR post types, respectively $(P=0.038$, and $P=0.042)$.

\section{Scanning electron microscopy observations}

Scanning electron microscopy evaluation revealed the presence of resin cements on the surface of the UV treated group compared with the control for both types of fiber posts. UV irradiation for 20 and

\begin{tabular}{|c|c|c|c|c|}
\hline Source & $d f$ & MS & $F$ & $P$ \\
\hline \multicolumn{5}{|l|}{ Bond strength KOR } \\
\hline Between groups & 3 & 43.29 & 3.45 & 0.042 \\
\hline Within groups & 16 & 12.5 & & \\
\hline Total & 19 & & & \\
\hline \multicolumn{5}{|l|}{ Bond strength FRC } \\
\hline Between groups & 3 & 18.02 & 3.54 & 0.038 \\
\hline Within groups & 16 & 5.08 & & \\
\hline Total & 19 & & & \\
\hline
\end{tabular}


15 min was evaluated for the FRC and KOR groups, respectively [Figure 3a-d].

\section{Surface roughness analysis}

The FRC post group was measured for surface roughness analysis. The KOR group was excluded because the post surface was serrated, and is thus unable to measure with AFM. Moreover, samples of FRC posts irradiated for 20 min were chosen because significantly higher SBS was observed with the above group. The mean roughness of the tested group was greater compared with that of the control group (without UV irradiation). However, significant differences were not observed $(P=0.061)$. Table 3 presents the mean value of surface roughness ( $\mathrm{Ra}$ ) in nanometers $(\mathrm{nm})$. Figure $4 \mathrm{a}$ and $\mathrm{b}$ shows the AFM images of surface roughness of the control and UV irradiated groups.

\section{DISCUSSION}

The null hypothesis that UV irradiation would not affect the bond strength of fiber-reinforced post and resin luting cement was rejected. The results revealed that the SBS of fiber-reinforced post to resin luting cement was significantly enhanced when the posts were exposed to UV irradiation for 20 and $15 \mathrm{~min}$ for the FRC and KOR types, respectively. Although other groups with different durations of UV exposure were not statistically significant compared with the control, SBS was consistently higher regardless of UV duration.

Application of UV to improve bond strength is effective, inexpensive, and very suitable for use, either clinically or in the laboratory. Based on our current observation from SEM images [Figure 3], resin cement was more evident on the surface of the UV treated post for both types, which supports a pattern of cohesive failure. These findings also support the theories of UV application on resin surface, which can cause molecular bonds to be broken when absorbed, a process referred to as photolytic chain scission, ${ }^{[23]}$ and can induce surface radicals that can be recombined to form various types of network and terminals groups. ${ }^{[24]}$ The cohesive failure pattern

Table 3: Result of surface roughness of FRC postec plus using AFM in contact mode

\begin{tabular}{lc}
\hline Surface treatment & Mean surface roughness (Ra) and SD \\
\hline No surface treatment & $275.8 \mathrm{~nm}(88.1)$ \\
UV irradiation for $20 \mathrm{~min}$ & $668.2 \mathrm{~nm}(246.7)$ \\
\hline SD: Standard deviation, AFM: Atomic force microscopy, UV: Ultraviolet
\end{tabular}

may be an evidence of development of the so called interpenetrating network "IPN" between the fiber post matrix resin and the resin cement matrix after

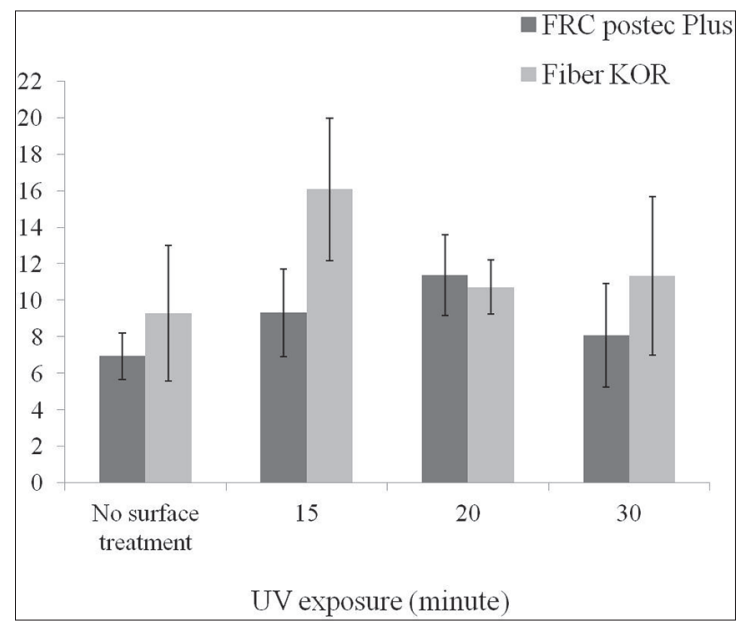

Figure 2: Result of shear bond strength MPa of two different fiber post with resin cement

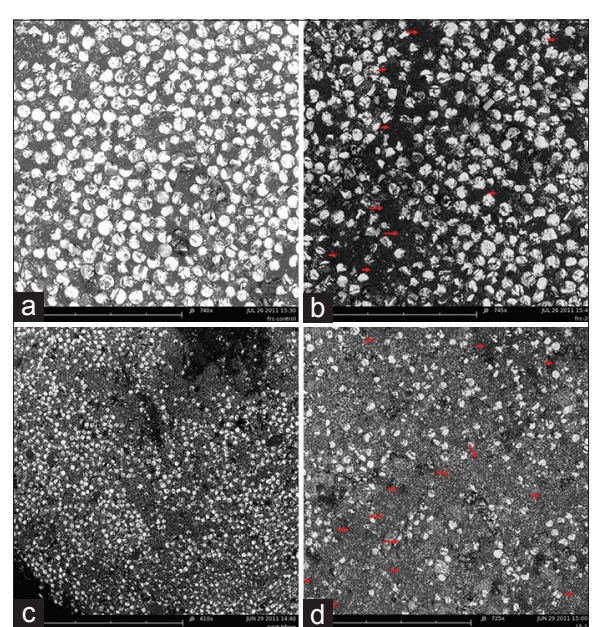

Figure 3: (a) Scanning electron microscopy (SEM) observation of (FRC) fiber post surface in control group without ultraviolet (UV) irradiation; (b) SEM observation of debonded FRC fiber post surface of 20 min UV irradiated group-arrows showing presence resin cements (darker areas) following debonding indicates cohesive failure; (c) SEM observation of KOR fiber post surface in control group without UV irradiation; (d) SEM observation of debonded KOR fiber post surface of $15 \mathrm{~min}$ UV irradiated group-arrows showing presence resin cements (darker areas) following debonding indicates cohesive failure

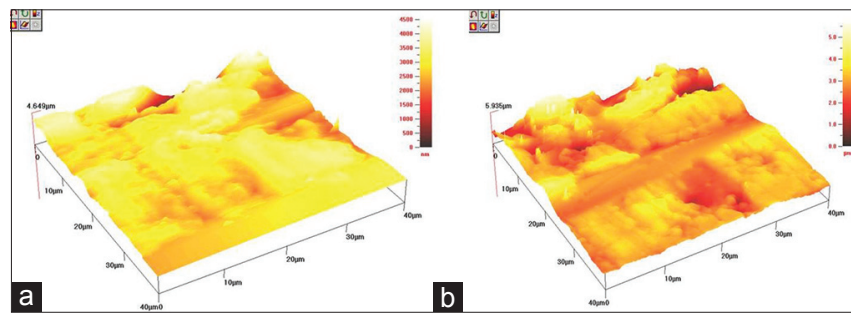

Figure 4: (a) Atomic force microscopy (AFM) image of FRC specimen with no surface treatment (control); (b) AFM image fiber post surface in 20 min ultraviolet irradiation group 
UV irradiation although the fiber post resin matrix is a thermosetting type. The bond strength of composite resins may be affected by restoration preparation technique, surface conditioning or curing of the bonding agent. ${ }^{[25]}$ This study supports the changes in bond strength of the fiber post with resin cements after surface conditioning of the post surface through UV irradiation.

A probable alteration of the bonding mechanism after UV application to the fiber-reinforced post at different time spans may be observed because SBS was higher compared with the control group. For 20 and 15 min of UV irradiation, a significant increase in SBS was observed for the FRC and KOR groups, respectively. However, the tendency of a slight decline of SBS was observed when the fiber posts were irradiated for $30 \mathrm{~min}$. This finding supports the previous study, ${ }^{[16]}$ which found that exposing glass fiber post to UV irradiation in a relatively short period could significantly improve the micro tensile bond strength of the resin cement to the epoxy-based glass fiber post. Longer duration would lead to more amount of energy being irradiated, which consequently causes the destruction of the chemical bonding. Reduced SBS caused by longer UV irradiation for $30 \mathrm{~min}$ was observed in this particular study.

Sensitive devices, such as $\mathrm{XPS}^{[26]}$ or an AFM, ${ }^{[27]}$ would better detect the changes at the UV irradiated surface ${ }^{[16]}$ because these could analyze a shallower surface. Any change in surface roughness after UV irradiation was detected using AFM in the present study. The surface roughness of post surface increased after UV irradiation; the changes in surface roughness of the fiber post at nanometer level were confirmed to contribute on bond strength improvement by increasing bonding area in addition to creating a mechanical interlock with minimum or no physical damage of the fiber post surface. The roughness value for the KOR group was not evaluated because the post had a serrated surface. Moreover, roughness analysis for all groups with FRC post type having different duration of UV exposures could be more informative. Recent fiber posts in the market have different shapes and surface topography that affect bond strength measurement. The top surface of fiber posts was flat and no influential factor, such as post shape or surface topography, on bond strength measurement is present; thus, the condition was considered ideal to measure SBS with resin cement in this study.

Composites with different organic matrix compositions demonstrated variations in bond strength values. ${ }^{[28]}$ The above fact is relevant while analyzing the bond strength results, given that a substantial amount of poly-methacrylate resin matrix (UDMA, TEGDMA) is observed in the composition of fiber post and resin cement. The FRC group contains $61 \%$ of fibers, while the fiber matrix ratio is very low at about $41 \%$ for the KOR group. ${ }^{[29]}$ Application of UV could initiate the photolytic chain scission and induce free radicals within the resin group; thus, more free radicals could be induced in the KOR group because of its higher percentage of resin in the composition and comparatively higher SBS observed with the aforesaid with different durations of UV irradiation.

The result of the bond strength may be influenced by several factors, such as the type of post and cement used. ${ }^{[30]}$ Cyclic loading and thermal cycling could be applied to simulate the aging process. The timing of the SBS measurement also plays an important role. Longer duration of about 3-7 days would result in better SBS. In the present study, SBS measurements were conducted within $2 \mathrm{~h}$ after the resin cemented the with fiber post. The measurement timing was designed to simulate the clinical situation because the endodontic post must be used soon after it is cemented. Further investigations are suggested to assess the effect of UV exposure on different types of the resin matrix in fiber post composition and evaluation of bond strength to different resin cements.

\section{CONCLUSIONS}

Within the limitation of this study, significantly higher SBS was observed between fiber-reinforced post and resin luting cement with UV irradiation for 15 and $20 \mathrm{~min}$; changes in surface roughness of the fiber-post were detected after UV irradiation. The increase in surface roughness of the fiber post causes mechanical interlock, although it was detected at nanometer level. Moreover, the presence of resin cements on the post surface after SBS measurement supports the chemical and physical changes of the fiber post surface of the UV irradiated group.

\section{ACKNOWLEDGMENTS}

The authors would like to thank all the staff of the Biomaterial and Craniofacial Laboratory, School of Dental Sciences, Universiti Sains Malaysia. This study was supported by a Universiti Sains Malaysia's short term grant 304/ PPSG/61313006. 


\section{REFERENCES}

1. Ayad MF, Bahannan SA, Rosenstiel SF. Influence of irrigant, dowel type, and root-reinforcing material on fracture resistance of thin-walled endodontically treated teeth. J Prosthodont 2011;20:180-9.

2. Asmussen E, Peutzfeldt A, Heitmann T. Stiffness, elastic limit, and strength of newer types of endodontic posts. J Dent 1999;27:275-8.

3. Ferrari M, Vichi A, García-Godoy F. Clinical evaluation of fiber-reinforced epoxy resin posts and cast post and cores. Am J Dent 2000;13:15B-8.

4. Schwartz RS, Robbins JW. Post placement and restoration of endodontically treated teeth: A literature review. J Endod 2004;30:289-301.

5. Cheleux N, Sharrock P, Degrange M. Surface treatments on quartz fiber post: Influence on adhesion and flexural properties. Am J Dent 2007;20:375-9.

6. de Durâo Mauricio PJ, González-López S, Aguilar-Mendoza JA, Félix S, González-Rodríguez MP. Comparison of regional bond strength in root thirds among fiber-reinforced posts luted with different cements. J Biomed Mater Res B Appl Biomater 2007;83:364-72.

7. Bell AM, Lassila LV, Kangasniemi I, Vallittu PK. Bonding of fibre-reinforced composite post to root canal dentin. J Dent 2005;33:533-9.

8. Kulunk S, Kulunk T, Yenisey M. Effects of different surface pre-treatments on the bond strength of adhesive resin cement to quartz fiber post. Acta Odontol Scand 2012;70:547-54.

9. Schmage P, Cakir FY, Nergiz I, Pfeiffer P. Effect of surface conditioning on the retentive bond strengths of fiberreinforced composite posts. J Prosthet Dent 2009;102:368-77.

10. D'Arcangelo C, D'Amario M, Prosperi GD, Cinelli M, Giannoni M, Caputi S. Effect of surface treatments on tensile bond strength and on morphology of quartz-fiber posts. J Endod 2007;33:264-7.

11. Yenisey M, Kulunk S. Effects of chemical surface treatments of quartz and glass fiber posts on the retention of a composite resin. J Prosthet Dent 2008;99:38-45.

12. Costa Dantas MC, do Prado M, Costa VS, Gaiotte MG, Simão RA, Bastian FL. Comparison between the effect of plasma and chemical treatments on fiber post surface. J Endod 2012;38:215-8.

13. Borcia C, Dumitrascu N, Borcia G. Comparing the modification induced by plasma and UV radiation to polymer surfaces. Rom Rep Phys 2012;64:163-72.

14. Yavirach $\mathrm{P}, \mathrm{Chaijareenont} \mathrm{P}$, Boonyawan D, Pattamapun K, Tunma S, Takahashi H, et al. Effects of plasma treatment on the shear bond strength between fiberreinforced composite posts and resin composite for core buildup. Dent Mater J 2009;28:686-92.

15. Loyaga-Rendon PG, Takahashi H, Iwasaki N, Reza F. Effect of ultraviolet light irradiation on bonding of experimental composite resin artificial teeth. Dent Mater J 2007;26:805-13.

16. Zhong B, Zhang Y, Zhou J, Chen L, Li D, Tan J. UV irradiation improves the bond strength of resin cement to fiber posts. Dent Mater J 2011;30:455-60.

17. Kuang P, Lee JH, Kim CH, Ho KM, Constant K. Improved surface wettability of polyurethane films by ultraviolet ozone treatment. J Appl Polym Sci 2010;118:3024-33.
18. Teare DO, Ton C, Bradley RH. Surface characterization and ageing of ultraviolet-ozone-treated polymers using atomic force microscopy and x-ray photoelectron spectroscopy. Surf Interface Anal 2000;29:276-83.

19. Landete-Ruiz MD, Martín-Martínez JM. Surface modification of EVA copolymer by UV treatment. Int J Adhes Adhes 2005;25:139-45.

20. Romero-Sànchez MD, Pastor-Blas MM, Martin-Martinez JM. Addition of ozone in the UV radiation treatment of a synthetic styrene-butadiene-styrene (SBS) rubber. Int J Adhes Adhes 2005;25:358-70.

21. Mailhot B, Thérias SM, Ouahioune M, Gardette JL. Study of the degradation of an epoxy/amine resin, 1 photo-and thermo-chemical mechanisms. Macromol Chem Phys 2005;206:575-84.

22. Monticelli F, Toledano M, Osorio R, Ferrari M. Effect of temperature on the silane coupling agents when bonding core resin to quartz fiber posts. Dent Mater 2006;22:1024-8.

23. Buchman A, Dodiuk H, Rotel M, Zahavi J. Laser-induced adhesion enhancement of polymer composites and metal alloys. In: Mittal KL, editor. Polymer Surface Modification: Releven to Adhesion. Utrecht: VSP; 1996. p. 199-212.

24. Kaczmarek H, Chaberska H. The influence of UV irradiation and support on surface properties of poly (methylmathacrylate) thin films. Appl Surf Sci 2006;252:8185-92.

25. Zorba YO, Ilday NO, Bayindir YZ, Demirbuga S. Comparing the shear bond strength of direct and indirect composite inlays in relation to different surface conditioning and curing techniques. Eur J Dent 2013;7:436-41.

26. Hillborg H, Tomczak N, Olàh A, Schönherr H, Vancso GJ. Nanoscale hydrophobic recovery: Achemical force microscopy study of UV/ ozone-treated cross-linked poly (dimethylsiloxane). Langmuir 2004;20:785-94.

27. Nie HY, Walzak MJ, Melntyre NS. Atomic force microscopy study of UV/ozone treated polypropylene films. In: Mittal KL, editor. Polymer Surface Modification: Relevance to Adhesion. Utrecht: VSP; 2000 p. 377-92.

28. Spyrou M, Koliniotou-Koumpia E, Kouros P, Koulaouzidou E, Dionysopoulos P. The reparability of contemporary composite resins. Eur J Dent 2014;8:353-9.

29. Seefeld F, Wenz HJ, Ludwig K, Kern M. Resistance to fracture and structural characteristics of different fiber reinforced post systems. Dent Mater 2007;23:265-71.

30. Farina AP, Cecchin D, Garcia Lda F, Naves LZ, Pires-de-Souza Fde C. Bond strength of fibre glass and carbon fibre posts to the root canal walls using different resin cements. Aust Endod J 2011;37:44-50.

\begin{tabular}{|l|l|}
\hline \multicolumn{2}{|c|}{ Access this article online } \\
\hline Quick Response Code: & Website: \\
& www.eurjent.com \\
& \\
&
\end{tabular}

